\title{
Bovine brucellosis: Seroepidemiology and herder's knowledge, attitude and practices in Bench Maji zone, southern Ethiopia
}

\author{
Tigist Kenea ${ }^{1}$, Bekele Megersa ${ }^{2 *}$ \\ ${ }^{1}$ Mizan Regional Diagnostic Laboratory, Mizan, Ethiopia \\ ${ }^{2}$ Addis Ababa University, College of Veterinary Medicine and Agriculture, Bishoftu Ethiopia. \\ *Correspondent email: Dr. Bekele Megersa: bekelebati@gmail.com
}

\begin{abstract}
Brucellosis is a major public and animal health problem in many parts of the world, particularly in pastoral settings where livestock is a major livelihood and food sources. Effective prevention and control of brucellosis depends on knowledge, attitude and practices of the community. This cross-sectional study was conducted between November 2018 and April 2019 in Bench Maji zone, with the objectives of investigating the prevalence and associated risk factors of bovine brucellosis, and assessing the knowledge and practices of herders. A questionnaire survey $(n=300)$ and collection of blood samples $(n=772)$ were carried out. The sera samples were screened using Rose Bengal Plate Test (RBPT) and positive ones were further confirmed by using Complement Fixation Test (CFT). Results showed that 25 (3.24\%) and 15 (1.94\%) of the 772 animals were positive for RBPT and CFT. This shows an overall sero-prevalence of $1.94 \%$, (95\% CI: 0.97- 0.2.92\%) bovine brucellosis in the study area. The highest prevalence, $2.74 \%$, was recorded at Menitshasha district while no positive case was recorded at Menitgoldiya districts. Large herd size $(\mathrm{OR}=4.7)$ and migration $(\mathrm{OR}=3.52)$ showed association with seropositivity. Cows with abortion history had higher likelihood of seropositive than other groups. Majority of the pastoralists (72.7\%) did not have information and basic knowledge about brucellosis, whereas about $27.3 \%$ of them heard about it and very small proportion (3.3\%) knew its zoonotic importance. All of the respondents were practicing high risk behavior of acquiring the infection. Demographic factors such as education, family size and age of herders were found to have effects on knowledge of herders. Low level of knowledge, high-risk practices and willingness of herders to know more about brucellosis call for improving public awareness on zoonotic significance of the diseases through integrating animal health and public health extension services.
\end{abstract}


Keywords: Attitude, Bovine; Brucellosis; Ethiopia, Knowledge; Practices; Prevalence; Risk factors

\section{Introduction}

Brucellosis is perhaps one of the most widespread and economically important diseases in tropical and subtropical countries such as Ethiopia. The disease can cause substantial economic losses at household and national levels. The direct loss of meat (because of abortion, infertility and weight loss) in infected herds of cattle was estimated to be $15 \%$ and for milk (reduction in milk production) 20\% per infected cow (Mangen et al., 2002; Nicoletti, 2010).

Brucellosis is a sub-acute or chronic disease which may affect wild and domestic animals such as cattle, sheep, goats, camels, equines and pigs with infection localizing in the reproductive system and causing abortion in the pregnant animals (Radostits et al., 2007). Clinically, infection is characterized by one or more of the following signs: abortion, retained placenta, orchitis, epididymitis and, rarely, arthritis. Abortions are more prevalent and numbers of organisms shed are much greater in unvaccinated animals (OIE, 2018).

The potential economic and public health impacts of brucellosis are overwhelmingly masked by many more priority diseases in developing countries with limited resources, including Ethiopia. Thus, the disease has not yet get full attention and preventions programs featuring any aspects of brucellosis interventions were not instituted (FAO, 2011). The epidemiology and economic impacts and cost of effective prevention measures of the disease in livestock and humans are not well studied in extensive production system. Brucellosis is known to cause abortion in livestock with the subsequent excretion of a large number of organisms which are easily acquired by other animals. The disease remains endemic and continues to pose public and animal health risks in subSaharan Africa of the world (Mangen et al., 2002).

Brucella infection is readily transmissible to humans, causing acute febrile illness - undulant fever - which may progress to a more chronic form involving musculo-skeletal, cardiovascular, and central nervous systems complication (OIE, 2018). In particular, brucellosis constitutes significant public health importance for a pastoral community where there is prevailing close contact with animals, raw milk and whole blood consumption practices and low awareness on the disease thereby leading to zoonotic transmission of the disease. Milk is 
a major staple food, consumed raw by almost all the pastoral community and be a source of infection with milk-borne zoonosis such as brucellosis.

In Ethiopia, although information on how and when brucellosis was introduced to the country is not established, the disease remains endemic. Several serological surveys have showed bovine brucellosis is an endemic and widespread disease in urban, per-urban, highland and lowland, extensive and intensive farming, smallholder farms and ranches of the country (Dinka and Chala, 2009, Jergefa et al., 2009; Mekonnen et al., 2011; Degefu et al., 2011; Asmare et al., 2013). Most of studies so far conducted on cattle brucellosis have been concentrated in central and northern Ethiopia, and do not provide an adequate epidemiological picture of the disease in different agro-ecological zones and livestock production systems of the country (Megersa et al., 2011).

Pastoralists or agro-pastoral communities have greater vulnerability to brucellosis because of close contact with animals during husbandry practices and consumption of animal products in addition to their marginalization from public services and information. On the other hand, these communities have significant contribution to national gross domestic products (GDPs) by making marginal lands more productive (Zinsstag et al., 2006). In view of that, understanding the seroepidemiology of bovine brucellosis in the pastoral and agro pastoral system of Bench Maji zone, and the extent of herder's knowledge and practices related to brucellosis would help in developing disease control strategies. Therefore, this study was aimed at estimating the seroprevalence of bovine brucellosis and associated factors and assessing brucellosis related knowledge, attitude and practices of livestock keeper in the study area.

\section{Materials and methods}

\section{Description of study Area}

This study was carried out between November 2018 and April 2019 in three selected districts of Bench Maji zone of SNNPRs. The capital town of the zone is located about $561 \mathrm{~km}$ from Addis Ababa in south western part of the country. The zone is found within latitude and longitude ranges of $34^{\circ} 45^{\prime}$ to $36^{\circ} 10^{\prime}$ east and $5^{\circ} 40^{\prime}$ to $7^{\circ} 40^{\prime}$ north. It is bordered with South Sudan Republic in southwest. Based on altitude range, the study areas were broadly classified into the different agro-climatic classifications: 52\% lowland "Kola" (<1500 m.a.s.l.); 43\% midland "Weynadega" (1500 to 2300 m.a.s.l.) and 5\% highland "Dega" (> 2300 
m.a.s.l.). The annual average temperature ranges from $15.1^{\circ} \mathrm{C}$ to $27.5^{\circ} \mathrm{C}$, while the annual rainfall ranges from 400 to $2,000 \mathrm{~mm}$ (Zone Agricultural Office, 2012). The study districts Maji and Menitgoldiya practice agro-pastoral production whereas Menitshasha practices more of pastoral production system.

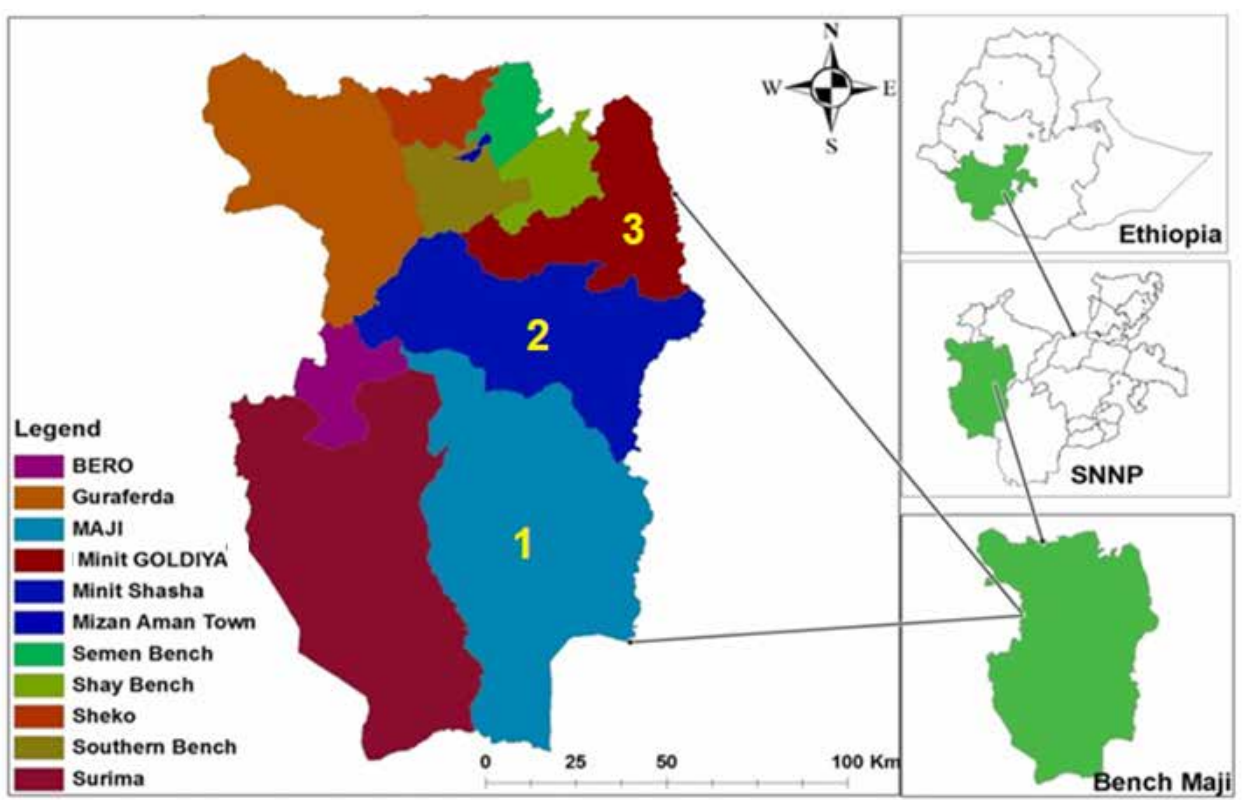

Fig.1: Map of Ethiopia showing the study area (labeled Maji=1, Menitshasha=2, Menitgoldiya=3)

\section{Study population and sampling methods}

The target populations for animals were Cattle in Bench Maji zone which are kept under different production system mainly pastoral or agropastoral systems. The study units were comprised of indigenous cattle in three selected districts in Bench Maji zone, which are kept under extensive production system. Both sexes and age groups of more than six months of age were selected for the study. Age were estimated by examining their lower incisor teeth according to Pace and Wakeman (2003) and also by asking the owners, then and categorized as young ( $<4$ years) and adults ( $\geq 4$ years). Since the study included questionnaire survey, the ethnicity herders in the zone are predominantly Bench, Menit, Dizi, Sheko, Surma, and Zelmamo. 
Animals were selected by multistage sampling methods. Three districts were purposively selected by considering agro-ecology and production system from which kebeles and animals were subsequently selected by random sampling method. The selected districts Menitshasha, Menitgoldia and Maji have 31, 24 and 20 kebeles, from which 4, 3 and 3 kebeles were selected, respectively. Starting from a presumed center of a kebele, we did a transect walk (which is a systematic walk along a specified route (we used the four cardinal directions) across the kebele together with an animal health worker. Then during transect traveling to different parts of the kebeles, encountered households were contacted and their animals were sampled randomly. A lottery system was used to select an individual animal from a herd, by assigning a number 1 (to be selected) or 0 (not to be selected) to an animal. Then those animals that had the chance for a number one were selected for bleeding until the required sample size for each kebele is fulfilled, so that nearly $50 \%$ of animals were selected from a herd.

\section{Sample size determination}

The sample size for each district was calculated by the formula recommended by Thrusfield and Christley, (2018) by assuming an expected prevalence of $20 \%$ and desired precision of $5 \%$ with $95 \%$ confidence interval which gave 246 animals. Since we used multistage sampling which requires a relatively large sample size, we increased the number of animals by three folds, making a total of 738 cattle. About 5\% contingency was added to compensate for any sample losses, mislabeling and discarding. The total sample size of this study was further stratified by each districts taking livestock population proportion of respective district. Finally, a total of 772 serum samples were collected and processed in the laboratory. Subsequently, nearly all animal owners (N=300 respondents) whose cattle sampled were included in the questionnaire survey.

\section{Serum sampling, testing, and questionnaire survey}

During blood sample collection factors like age, sex, altitude, parity, abortion/ stillbirth, herd size, distance from water point, and frequency of migration and production system were collected. About $10 \mathrm{ml}$ of blood sample was collected from the jugular vein of each animal using plain vacutainer tubes under aseptic condition. After 24 hours sera were separated and transferred to cryovial tubes, which were labeled and stored in deep freezer until tested. All serum samples were screened using Rose Bengal Plate Test (RBPT) at Mizan Re- 
gional Veterinary Diagnostic Laboratory and positive samples were tested at National Veterinary Institute (NVI) using Complement Fixation Test (CFT). A questionnaire was designed to assess the knowledge, attitude and practice of animal owners ( $\mathrm{n}=300$ participants) on bovine brucellosis. The questionnaire focused on herder's knowledge, attitude and practices related to brucellosis was administered to herders. Firstly, herders were asked 11 questions (mainly yes or no, and sometimes multiple options) related to knowledge of herders on brucellosis, its mode of transmission, zoonotic importance, and prevention means. For example, "have you ever heard about brucellosis?" Secondly, they were asked 12 questions related to their attitude or belief such as "do you think boiling milk prevent brucellosis?". Then 17 questions related to practices of herders were asked, of which 11 questions were related to exposure (risky) practices i.e "Do assist delivery with bare hand?" The remaining 6 questions were related to preventive measures such as "do you cook meat for consumption?" Answering, a question properly guaranties the respondent with score of 1 or otherwise 0 . For instance, a respondent may obtain score ranging from 0 to 11 for knowledge questions, and score of 0 to 12 for attitude questions. Finally, after completing the questionnaire checking, correction and clarification were mad before leaving the village.

\section{Data management and analysis}

The data were entered into Microsoft Excel spread sheet 2010 program and statistical analysis was performed using STATA version 14 (Stata Corp, College Station, Texas). In addition to descriptive analysis, association of Brucella sero-positivity with risk factors was assessed using logistic regressions. Variables with $p$-value $<0.2$ in univariable analysis were included in multivariate logistic regression. Collinearity among the independent variables were checked using gamma statistics (a measure of rank correlation), and those with gamma coefficient within -0.6 and +0.6 were considered in multivariable logistic regression analysis. We used the Kruskal-Wallis $\mathrm{H}$ test (a rank-based nonparametric test) to analyze the effects of socio-demographic factors on knowledge, attitude and practice of respondents' towards bovine brucellosis. 


\section{Results}

\section{Socio-demography of the Respondents}

Out of 300 participants, 82 (27.3\%) of them were from Maji, 136 (45.3\%) from Menitshasha and $82(27.3 \%)$ were from Menitgoldiya districts. Participants belong to two ethnic groups: 218 (72.7\%) of them were Menit while $82(27.3 \%)$ were Dizi. Majority of the participants were agro-pastoralist, 161(53\%) were non-educated, while $43(14.3 \%)$ of them had attained primary education. About $45 \%$ of the participants were between ages 15 to 35 and the rest were above 35 years while $53 \%$ were males and $47 \%$ were females (Table 1 ).

Table 1. The socio-demography of study participants

\begin{tabular}{|c|c|c|c|}
\hline Variable & Category & Frequency & Percent (\%) \\
\hline \multirow[t]{3}{*}{ District } & Maji & 82 & 27.3 \\
\hline & Menitshasha & 136 & 45.3 \\
\hline & Menitgoldiya & 82 & 27.3 \\
\hline \multirow[t]{2}{*}{ Agro-ecology } & Midland & 164 & 54.7 \\
\hline & Lowland & 136 & 45.3 \\
\hline \multirow[t]{2}{*}{ Sex } & Male & 159 & 53.0 \\
\hline & Female & 141 & 47.0 \\
\hline \multirow[t]{3}{*}{ Age } & $18-35$ & 135 & 45.0 \\
\hline & $35-55$ & 88 & 29.33 \\
\hline & Above 55 & 77 & 25.67 \\
\hline \multirow[t]{3}{*}{ Education } & None educated & 161 & 53.67 \\
\hline & Read and write & 96 & 32.0 \\
\hline & Primary school & 43 & 14.33 \\
\hline \multirow[t]{2}{*}{ Ethnic group } & Dizi & 82 & 27.33 \\
\hline & Menit & 218 & 72.67 \\
\hline \multirow[t]{3}{*}{ Family size } & $3-5$ & 137 & 45.67 \\
\hline & $6-9$ & 106 & 35.33 \\
\hline & $>9$ people & 57 & 19.0 \\
\hline \multirow[t]{3}{*}{ Farming system } & Sedentary & 88 & 29.33 \\
\hline & Agro-pastoral & 143 & 47.67 \\
\hline & Pastoral & 69 & 23.0 \\
\hline
\end{tabular}

Ethiop. Vet. J., 2021, 25 (1), 23-42 


\section{Seroprevalence of bovine brucellosis and associated risk factors}

The serological test results show that 25 (3.24\%) of the tested animals were found positive by RBPT, which were further subjected to CFT testing. The overall individual animal level seroprevalence based on the confirmatory CFT test was $1.94 \%$ (95\%CI: $1.0-2.9$ ). The highest prevalence of $2.74 \%$ was recorded at Menitshasha, whereas no reactor was found at Menitgoldiya district.

Table 2 presents prevalence of animal level Brucella seropositivity and its association with exposure variables. Animals that kept in large herds were 4.7 times at risk of being seopositive than those from small herd size. Other factors such as altitude, age, sex, distance to water and migration of herds showed marginal association. Seroprevalence was about more than three folds in lowlands compared to highland, and adult animals were two times more likely to be seropositive than young ones. Migrating herds and those with shorter distance to water point had three times more likelihood of being seropositive than their counter parts. Females with history of abortion had higher likelihood of being seropositive than their counterparts. 
Table 2. Univariable analysis of potential risk factors associated with Brucella seropositivity

\begin{tabular}{|c|c|c|c|c|c|}
\hline $\begin{array}{l}\text { Variable } \\
\text { Category }\end{array}$ & $\begin{array}{l}\text { No. of cattle } \\
\text { tested }\end{array}$ & $\begin{array}{l}\text { No. of } \\
\text { cattle } \\
\text { positive }\end{array}$ & $\begin{array}{l}\text { Prevalence } \\
\text { (\%) }\end{array}$ & $\begin{array}{l}\text { Odd Ratio } \\
(95 \% \text { CI) }\end{array}$ & $p$-value \\
\hline \multicolumn{6}{|l|}{ District* } \\
\hline Maji & 130 & 3 & 2.31 & - & - \\
\hline Menitshasha & 438 & 12 & 2.74 & $1.19(0.33-4.29)$ & 0.788 \\
\hline Menitgoldiya & 204 & 0 & 0 & - & - \\
\hline \multicolumn{6}{|l|}{ Altitude } \\
\hline Lowland & 438 & 12 & 2.74 & - & - \\
\hline Midland & 334 & 3 & 0.89 & $0.32(0.09-1.14)$ & 0.081 \\
\hline \multicolumn{6}{|l|}{ Age } \\
\hline$<$ 4years & 544 & 8 & 1.47 & - & - \\
\hline$\geq$ 4years & 228 & 7 & 3.07 & $2.12(0.76-5.92)$ & 0.151 \\
\hline \multicolumn{6}{|l|}{ Sex } \\
\hline Male & 280 & 3 & 1.07 & $0.43(0.12-1.55)$ & 0.198 \\
\hline Female & 492 & 12 & 2.44 & - & - \\
\hline \multicolumn{6}{|l|}{ Abortion } \\
\hline Yes & 6 & 4 & 66.67 & $119.75(19.1-750.6)$ & 0.000 \\
\hline No & 487 & 8 & 1.64 & - & - \\
\hline \multicolumn{6}{|l|}{ Herd size } \\
\hline$<35$ cattle & 412 & 3 & 0.73 & - & - \\
\hline$\geq 35$ cattle & 360 & 12 & 3.33 & $4.70(1.32-16.79)$ & 0.017 \\
\hline \multicolumn{6}{|l|}{$\begin{array}{l}\text { Distance to } \\
\text { water }\end{array}$} \\
\hline Far & 330 & 3 & 0.91 & - & - \\
\hline Near & 442 & 12 & 2.71 & $3.04(0.85-10.87)$ & 0.087 \\
\hline \multicolumn{6}{|l|}{ Migration } \\
\hline Yes & 438 & 12 & 2.74 & $3.10(0.87-11.10)$ & 0.081 \\
\hline No & 334 & 3 & 0.89 & - & - \\
\hline
\end{tabular}

Variables such as age, sex, herd size, migration were retained in the final model, while altitude was excluded due to its collinearity with migration. Abortion was also excluded from the multivariable model as it only occurs in breeding females. The multivariable logistic regression model (Table 3) showed that animals kept in large herd sizes were more likely to be exposed to Brucella infections $(\mathrm{OR}=4.73,95 \% \mathrm{CI}=1.32$ - 16.98) than those maintained in small 
herds. Animals in migrating herds also showed marginal significance with three times more likelihood of seropositivity compared to other group.

Table 3. Multivariable logistic regression for selected variables

\begin{tabular}{lcccc}
\hline Variable category & OR & SE & CI (95\%) & p-value \\
\hline Age: (> 4 years) & 2.13 & 1.17 & $0.73-6.24$ & 0.167 \\
Sex: (male) & 0.49 & 0.33 & $0.13-1.85$ & 0.295 \\
Herd size: (large) & 4.73 & 3.08 & $1.32-16.98$ & $0.017^{*}$ \\
Migration: (yes) & 3.52 & 2.31 & $0.97-12.74$ & 0.055 \\
\hline
\end{tabular}

\section{Respondents' Knowledge, attitude and practices related to bovine brucellosis}

Out of 300 participants who were asked about the level of their knowledge of bovine brucellosis, large majority (72.67\%) of the herders do not have any information since they did not hear about brucellosis. About $17.3 \%$ of the participants responded to one to four knowledge questions, and $14.0 \%$ of them answered more than five questions correctly (Table 4). Accordingly, 82 (27.33\%) had heard of brucellosis and they mentioned veterinarians $16(5.33 \%)$ and community 66 (22\%) as their information source. For the question stated that, "is brucellosis considered as animal health problem in the area. Only few proportions $(4.3 \%)$ of the herders responded yes. 
Table 4. Respondents' knowledge on different aspects of Bovine Brucellosis $(n=300)$

\begin{tabular}{|c|c|c|c|c|}
\hline Knowledge of brucellosis & $\begin{array}{c}\text { Proportion } \\
\text { of affirmative } \\
\text { or correct } \\
\text { responses ( } \%)\end{array}$ & $\begin{array}{l}\text { Std. } \\
\text { Err. }\end{array}$ & & 95\% CL \\
\hline $\begin{array}{l}\text { Have you ever heard about } \\
\text { brucellosis? }\end{array}$ & 27.3 & 2.58 & 22.3 & 32.4 \\
\hline $\begin{array}{l}\text { Is brucellosis an animal health } \\
\text { problem in this area? }\end{array}$ & 4.3 & 1.18 & 2.0 & 6.7 \\
\hline $\begin{array}{l}\text { Which livestock species are } \\
\text { affected by brucellosis? }\end{array}$ & 27.3 & 2.58 & 22.3 & 32.4 \\
\hline $\begin{array}{l}\text { Clinical signs of brucellosis in } \\
\text { cattle }\end{array}$ & 20.7 & 2.34 & 16.1 & 25.3 \\
\hline $\begin{array}{l}\text { Does it transmit from animal to } \\
\text { animal? }\end{array}$ & 16.7 & 2.16 & 12.4 & 20.9 \\
\hline Mode of transmission to animal & 16.7 & 2.16 & 12.4 & 20.9 \\
\hline Does it cause illness in human? & 3.3 & 1.04 & 1.3 & 5.4 \\
\hline $\begin{array}{l}\text { Does it transmit from animal to } \\
\text { human? }\end{array}$ & 3.3 & 1.04 & 1.3 & 5.4 \\
\hline Mode of transmission to human & 3.3 & 1.04 & 1.3 & 5.4 \\
\hline Clinical signs in human & 3.3 & 1.04 & 1.3 & 5.4 \\
\hline $\begin{array}{l}\text { Which diseases have similar } \\
\text { signs? }\end{array}$ & 3.3 & 1.04 & 1.3 & 5.4 \\
\hline
\end{tabular}

Those who had information about brucellosis further responded to multiple option questions such as which animal species are affected by brucellosis. They responded that cattle 75 (25\%), sheep $12(4 \%)$, goats32 (10.67\%), equine $15(5 \%)$ and dogs $9(3 \%)$. The symptoms reported include retained placenta as most common sign (22.67\%), abortion (1.6\%) and stillbirth. The reported symptoms in human were sweating and joint pains. The diseases mentioned with similar signs were malaria (13.33\%), typhoid (7\%) and common cold (3.67\%).

Table 5 presents a Kruskal-Wallis $\mathrm{H}$ test result that was conducted to determine if participants' knowledge varied with socio-demographic variables such as district, age, sex, education, family size, ethnicity, farming system and agro ecology. The test showed that there was a statistically significant difference in knowledge between age, education and family size groups, with younger in- 
dividuals, people with elementary education and those with small family size having better knowledge than others.

Table 5. Kruskal-Wallis $H$ test of factors affecting knowledge

\begin{tabular}{|c|c|c|c|c|c|}
\hline Variable & Category & $\begin{array}{l}\text { No of } \\
\text { respondents }\end{array}$ & $\begin{array}{l}\text { Average } \\
\text { knowledge score }\end{array}$ & & p-value \\
\hline \multirow[t]{4}{*}{ District } & & & & $2.96(2)$ & 0.2274 \\
\hline & Maji & 82 & 2.12 & & \\
\hline & Menitshasha & 136 & 1.75 & & \\
\hline & Menitgoldiya & 82 & 2.05 & & \\
\hline \multirow[t]{3}{*}{ Sex } & & & & $2.06(1)$ & 0.1512 \\
\hline & Male & 159 & 1.74 & & \\
\hline & Female & 141 & 2.08 & & \\
\hline \multirow[t]{4}{*}{ Age } & & & & $45.42(2)$ & 0.0001 \\
\hline & 18-35 years & $135 \mid$ & 2.95 & & \\
\hline & 35-55years & 88 & 1.46 & & \\
\hline & Above 55 years & 77 & 0.72 & & \\
\hline \multirow[t]{4}{*}{ Education } & & & & $124.06(2)$ & 0.0001 \\
\hline & Non educated & 161 & 0.36 & & \\
\hline & $\begin{array}{l}\text { Read and } \\
\text { Write }\end{array}$ & 96 & 2.38 & & \\
\hline & Primary school & 43 & 4.49 & & \\
\hline \multirow{3}{*}{$\begin{array}{l}\text { Family } \\
\text { size }\end{array}$} & $3-5$ & 137 & 2.98 & $40.89(2)$ & 0.0001 \\
\hline & $6-9$ & 106 & 1.43 & & \\
\hline & above 9 & 57 & 0.84 & & \\
\hline \multirow{4}{*}{$\begin{array}{l}\text { Farming } \\
\text { system }\end{array}$} & & & & $2.55(2)$ & 0.2791 \\
\hline & Mixed & 88 & 1.71 & & \\
\hline & Agro-pastoral & 143 & 2.14 & & \\
\hline & Pastoral & 69 & 2.12 & & \\
\hline \multirow{3}{*}{$\begin{array}{l}\text { Agro- } \\
\text { ecology }\end{array}$} & & & & $0.51(1)$ & 0.4764 \\
\hline & Mid land & 164 & 2.12 & & \\
\hline & Low land & 136 & 1.85 & & \\
\hline
\end{tabular}

Herders had reflected positive attitude towards some questions e.g. "do you think brucellosis is treatable in animals?" in which $83 \%$ replied yes, but they thought it is not treatable in human. Similarly, considerable proportions also 
responded washing hands after contact with animals (49\%) and after assisting delivery (33\%) prevent brucellosis. Regarding treatment means of brucellosis they mentioned modern drug 85 (28.33\%), herbs 70 (23.33\%) and religious practices 95 (31.67\%). For the questions of prevention of brucellosis in animals $52(17.3 \%)$ responded brucellosis can be prevented in animals by vaccine and isolation of animals. But all of the respondents thought that boiling milk and cooking meat don't prevent brucellosis transmission in human. Most of the herders (83\%) reflected that they need more information on brucellosis.

Table 6. Respondents' attitude (positive attitude) towards brucellosis prevention

\begin{tabular}{lcc}
\hline Attitude of Respondents' & Yes (\%) & No (\%) \\
\hline Do you think & & \\
Boiling milk prevent brucellosis? & $0(0)$ & $300(100)$ \\
Cooking meat prevent brucellosis? & $0(0)$ & $300(100)$ \\
Hand washing after contact with animals prevent it? & $148(49.33)$ & $152(50.7)$ \\
Hand washing after assisting calving prevent it? & $99(33)$ & $201(67.0)$ \\
You need more information on brucellosis? & $249(83)$ & $51(17.0)$ \\
Brucellosis is treatable in human? & $0(0)$ & $300(100)$ \\
Brucellosis is treatable in animal? & $250(83.33)$ & $50(16.7)$ \\
Brucellosis can be prevented in animals? & $52(17.33)$ & $248(82.7)$ \\
\hline
\end{tabular}

Most of the respondents of the area indicated that they perform several exposures (risky) practices frequently such as all of them consume raw milk and meat and $39 \%$ of drink fresh blood. But they do very few preventive practices such as cooking meat and milk before consumption and proper hand washing after contacts with animals or discharges of potential contaminants (Table 7). 
Table 7. Respondents' Protective and Exposure Practices' towards Brucellosis

\begin{tabular}{lcc}
\hline Practice of respondents & Frequency & Percentage \\
\hline Exposure (risky) practices & 300 & 100 \\
Raw milk consumption & 40 & 13.3 \\
Drinking of milk from aborted cow & 300 & 100 \\
Consuming raw meat & 117 & 39.0 \\
Consuming fresh blood & 211 & 70.3 \\
Assisting delivery with bare hand & 75 & 25.0 \\
Removing placenta by bare hand & 141 & 47.0 \\
Handle aborted fetus with bare hand & & \\
Preventive practices & 26 & 8.7 \\
Cook meat for consumption & 50 & 16.7 \\
Boil milk for consumption & 97 & 32.3 \\
Separate cow during parturition & 29 & 9.7 \\
Separate aborted animals & 0 & 0.0 \\
Properly dispose fetal membrane & 19 & 6.3 \\
Wash hand with soap after delivery & & \\
\hline
\end{tabular}

Table 8 shows the mean score estimation of herders' knowledge, positive attitude, and practices (exposure and protective ones) with regard to brucellosis. The mean score of herders' knowledge was moderately low with 2.08 out of 11 scores. Respondents had generally good attitudes (5.57), but performing high level of risky practices (7.52) that can expose them to infection and at the same times they undertake low protective measures (2.48). In general, respondents had low level of information on bovine brucellosis, thus perform high risky practices while taking meager prevention measures.

Table 8. Estimation, of mean score of knowledge (out of maximum score of 11), attitudes (out of maximum score of 12), exposure (out of maximum score of11) and protective (out of maximum score of 6) practices regarding brucellosis

\begin{tabular}{lccc}
\hline Variable & Mean & SE & $\mathbf{9 5 \% ~ C I ~}$ \\
\hline Knowledge & 2.08 & 0.21 & $1.66-2.50$ \\
Good attitude & 5.57 & 0.20 & $5.18-5.97$ \\
Risky practices & 7.52 & 0.11 & $7.31-7.73$ \\
$\begin{array}{l}\text { Protective } \\
\text { practices }\end{array}$ & 2.48 & 0.10 & $2.48-2.89$ \\
\hline
\end{tabular}




\section{Discussion}

The study showed that seropositivity to Brucella infection was detected in two of the three study districts. The overall seroprevalence of $1.96 \%$ was comparable to the findings of several other authors in Ethiopia such as $1.66 \%$ in Sidama zone (Asmare et al., 2010), 1.41\% in Jijjiga zone (Degefu et al., 2011), 1.97\% in East Wollega zone (Yohannes et al., 2012), 2.0\% from Debrezeit (Alemu et al., 2014). But it is lower than other reports from Ethiopia such as 3.5\% from pastoral and mixed farming (Megersa et al., 2011), 11.2\% from East Showa (Dinka and Chala, 2009), 8.0\% from Borana area (Megersa et al., 2012), and $6.1 \%$ from Tigray (Mekonnen et al., 2011).

Factors such as migration showed marginal association with seropositivity in that herds that migrate at least once a year had three times more likelihood of being seropositive than others. Mobile herds have high chances of coming in contact with other herds and wildlife so that more likely acquire infections than non-migrating ones (Megersa et al., 2011). The observed higher seropositivity in the large herds is in line with previous study findings (Megersa et al., 2011; Mekonnen et al., 2011) and can be attributable to increase in stocking density and frequent contacts among animals in large herds, one of the determinants for exposure to Brucella infection especially during the time of abortion or calving (Radostits et al., 2007).

Results of herders' knowledge, attitude and practices about brucellosis showed that most of the livestock keepers didn't have adequate knowledge about brucellosis in general and transmission of brucellosis to human through consumption of raw milk and meat, fresh blood, as well as its prevention measures. Our finding is similar to a previous study report from Borana pastoral communities (Roba, 2017). Another study from Ecuador (Ruano and Aguayo, 2017) also reported that only a small proportion of respondents $(0.6 \%$ to $30.2 \%)$ stated to have knowledge about different aspect of brucellosis, while about $29.8 \%$ of the respondents indicated that they knew the clinical signs of the disease in cattle. Low level of knowledge on the disease and wide prevalence of behavioral risk (exposure) such consumptions of raw milk, fresh blood and raw meat, and assisting delivery without proper protection certainly expose pastoralists to brucellosis and clearly show the public health importance of the disease in the study areas. 
The information on the zoonotic importance of brucellosis is not known by the community in the present study area, since more than three quarters of the respondents had not heard of Brucellosis. This shows low level of herders knowledge compared to reports from Uganda (Kansime et al., 2014) among pastoral communities living along lake Mburo; in Egypt among cattle and Buffalo farmers in a village in Nile Delta region (Holt et al., 2011) and among small ruminant farmers in the peri-urban areas of Dushanbe Tajikistan (Lindahl et al., 2015 in which $99.3 \%, 83.2 \%$ and $57 \%$ of the respondents' had heard of Brucellosis and its zoonotic importance. The current finding on the animal species affected by brucellosis was fairly in agreement with a study in Tajikistan (Lindahl et al., 2015) in which two thirds of the livestock keepers mentioned that all animals could be affected.

Analyses on various factors that have potential influence on knowledge of herders showed that age, education and family size were associated with the knowledge of farmers. Younger individuals with age groups of 18 to 35 and those with having smaller family size had better knowledge of brucellosis than their counterparts, which might be explained by high inquisitive nature of younger people and with possibility of possessing information source device such as mobile phone and radio. The effects of educations have been reported by other authors elsewhere such by Ruano and Aguayo, (2017) in which greater knowledge about brucellosis was observed among people with a higher educational level. Similarly, a study by Lindahl et al. (2015) also showed that low level of education was significantly associated with poor knowledge of brucellosis.

The main sources of information on brucellosis in this study area were colleagues in community followed by animal health workers. Similarly, a study by Kansiime et al., (2014) showed that most of the respondents (91.4\%) in Uganda had heard about brucellosis in their area of residence mainly from friends in the community. According to Lindahl et al. (2015) respondents in Tajikistan who talked about animal health issues with veterinarians had more likely to hear about brucellosis than those who discuss with family members or friends. This suggests the impact of animal health workers and veterinarians in creating awareness among herders on zoonotic diseases. But our finding of lower proportion information source from animal health workers implies the limited roles of veterinarians in conveying important animal health messages to herders of the area who in most cases do not fairly access basic education and health care services. There is a need for integrating animal health extension into human health extension with regard to zoonotic diseases. 
With regards to clinical signs of brucellosis in animals, $26 \%$ respondents mentioned retained placenta and $22.7 \%$ abortion as the major clinical sign. This finding is in agreement with a study finding from Kaduna state of Nigeria (Buhari et al., 2015) and the study in Egypt (Holt et al., 2011) in which 94.4\% and $59.5 \%$ of respondents mentioned abortion as the major clinical sign. Unlike result of the present study, Lindahl et al. (2015) reported from Tajikistan only $11 \%$ of respondents mentioned abortion as a clinical sign of Brucellosis in the animals.

Regardless of their low level of information on brucellosis, herders had higher positive attitude towards some attitude questions, might be by chance or could be extrapolated from the general knowledge of herders on other livestock diseases. For instance, they might assume that all livestock diseases may have medications and prevention means so that considerable proportion of herders thought brucellosis can be treated or prevented. But since practices of herders depend on their knowledge of the disease, the poor the knowledge the lower the protective practices. Most of the herders consumed unpasteurized dairy products, raw meat and fresh blood more frequently, which are known to be important risk factor for human infections (Lindahl et al., 2015). A majority of the livestock keepers in the current study area did not use protective gloves when assisting delivery and handling cows having an abortion or with aborted materials or did not properly wash their hands similar to observation by Lindahl et al. (2015) who reported such practices due to poor knowledge of herders on the zoonotic role of brucellosis.

\section{Conclusions}

The observed seroprevalence of 1.94 (95\% CL: 1.0- 2.9) at individual animal level in the study area can be regarded as low prevalence but has public health significance. Factors such as herd size and migrating herds seem to be important risk factors that should be considered in disease control. Livestock keepers of the study area had low level of basic knowledge about bovine brucellosis and undertake insufficient disease prevention measures. Enhanced public health education on the cause, symptoms and mode of transmission of brucellosis would be important towards the prevention and control of the disease in the present study area. This can be achieved by creating awareness of the community on control and prevention of zoonotic diseases in the context of "One Health approach". 


\section{Acknowledgment}

Authors are thankful to Mizan Regional Veterinary Laboratory for providing laboratory facilities and technical assistance during the study. The willingness of livestock keepers to participate in the study and critical comments of the anonymous reviewers are highly appreciated.

\section{References}

Alemu, F., Admasu, P., Feyera, T., Niguse, A. 2014. Seroprevalence of bovine brucellosis in Eastern Showa, Ethiopia. Acad. J. Anim. Dis., 3 (3), 27-32.

Asgedom, H., Damena, D. and Duguma, R. 2016. Seroprevalence of bovine brucellosis and its associated risk factors in and around Alage district, Ethiopia. Springer plus, 5:851

Asmare, K., Asfaw, Y., Gelaye, E., Ayelet, G. 2010. Brucellosis in extensive management system of Zebu cattle in Sidama Zone, Southern Ethiopia. Afr. J. Agric. Res., 5, 257-263.

Asmare, K., Sibhat, B., Molla, W., Ayelet, G., Shiferaw, J., Martin, A.D., Skjerve, E. and Godfroid, J. 2013. The status of bovine brucellosis in Ethiopia with special emphasis on exotic and cross bred cattle in dairy and breeding farms. Act. Trop., $126,186-192$.

Bekele, A., Molla, B., Asfaw, Y., Yigezu, L. 2000. Bovine brucellosis in ranches and farms in southeastern Ethiopia. Bull. Anim. Hlth. Prod. Afr.,48, 1317.

Buhari, H.2015. Knowledge, attitude and practices of pastoralists on bovine brucellosis in the north senatorial district of Kaduna state, Nigeria. J. Anim. Hlth Prod., 3(2), 28-34.

Degefu, H., Mohamud, M., Hailemelekot, M. and Yohannes, M. 2011. Seroprevalence of bovine brucellosis in agro pastoral areas of Jijjiga zone of Somali National Regional State, Eastern Ethiopia. Ethiop. Vet. J., 15 (1), 37-47.

Dinka, H. and Chala, R. 2009. Seroprevalence Study of Bovine Brucellosis in Pastoral and Agro-Pastoral Areas of East Showa Zone, Oromia Regional State, Ethiopia. Am. Eurasian J. Agric. Environ. Sci., 6, 508 - 512

Food and Agriculture Organization of the United Nations, (FAO) 2011. Guidelines for coordinated human and animal brucellosis surveillance. FAO Anim. Prod. Hlth No.156, pp 45.

Holt, H.R., Eltholth, M.M., Hegazy, Y.M., El-Tras, W.F., Taye, A.A., Guitian, J. 2011. Brucella spp. infection in large ruminants in an endemic area of Egypt: cross- 
sectional study investigating seroprevalence, risk factors and livestock owner's knowledge, attitudes and practices (KAPs). BMC Public Hlth.,11, 341.

Jergefa, T., Kelay, B., Bekana, M., Teshale, S., Gustafson, H. and Kindahl, H. 2009. Epidemiological study of bovine brucellosis in three agro-ecological areas of central Oromia, Ethiopia. Rev. Sci. Tech. Off. Int. Epiz., 28, 933-943.

Kansiime, C., Mugisha, A., Makumbi, F., Mugisha, S., Rwego, I.B., Sempa, J., Kiwanuka, S.N., Asiimwe, B.B., and Rutebemberwa, E. 2014. Knowledge and perceptions of brucellosis in the pastoral communities adjacent to Lake Mburo National Park, Uganda. BMC public hlth., 14, 242.

Lindahl, E., Sattorov, N., Boqvist, S., Magnusson, U. 2015. A Study of Knowledge, Attitudes and Practices Relating to Brucellosis among Small-Scale Dairy Farmers in Urban and Peri-Urban Area of Tajikistan. PloS one,10 (2).

Mangen, M.J., Otte, J., Pfeiffer, D., Chilonda, P. 2002. Bovine brucellosis in sub-Saharan Africa: estimation of seroprevalence and impact on meat and milk offtake potential. Livestock Policy Discussion Paper No. 8, FAO, Rome.

Megersa, B., Biffa, D., Niguse, F., Rufael, T., Asmare, K., Skjerv, E. 2011. Cattle brucellosis in traditional livestock husbandry practice in Southern and Eastern Ethiopia, and its zoonotic implication. Acta Veterinaria Scandinavica, 53:24

Megersa, B., Biffa, D., Abunna, F., Regassa, A., Godfroid, J. and Skjerve, E., 2012. Seroepidemiological study of livestock brucellosis in a pastoral region. Epidemiol. Infect., 140 (5), 887-896.

Mekonnen, H., Shewit, K., Moses, K., Mekonnen, A., Belihu, K. 2011. Effect of Brucella infection on reproduction conditions of female breeding cattle and its public health significance in western Tigray, northern Ethiopia. Vet. Med. Int., 2011(2):354943.

Nicoletti, P., 2010. Brucellosis: past, present and future. Prilozi, 31(1):21-32.

Office International des Epizooties (OIE) 2013. Bovine brucellosis: Manual of diagnostic tests and vaccines for terrestrial animals OIE, Paris; 409-435.

Pace, J.E., and Wakeman, D.L. 2003. Determining the Ages of Cattle by Their Teeth. University of Florida, IFAS Extension.

Radostits, O.M., Gay, C.C., Hinchcliff, K.W., Constable, P.D. 2007. Veterinary Medicine: A textbook of the diseases of cattle, horses, sheep, pigs and goats. $11^{\text {th }}$ ed. London: WB Saunders Company Ltd.

Roba, J. 2017. Brucellosis in Borena Cattle: Seroprevalence and Awareness of the Pastoral Community in Yabello, Ethiopia. MSc Thesis, College of Veterinary Medicine and Agriculture, Addis Ababa University, Bishoftu, Ethiopia.

Ethiop. Vet. J., 2021, 25 (1), 23-42 
Ruano, M. P., and Aguayo, M.D., 2017. Study of Knowledge about Bovine Brucellosis among people involved in the cattle supply chain in the Province of Manabí, Ecuador. Rev Sci Tech., 36(3), 917-925.

Seleem, M.N., S.M. Boyle, N. and Sriranganathan, N. 2010. Brucellosis: a re-emerging zoonosis. Vet. Microbiol., 140(3), 392-398

Thrusfield, M. and Christley, R. 2018. Veterinary Epidemiology. $4^{\text {th }}$ ed. John Wiley and sons Ltd, The Atrium, South Gate, Chichester, West Sussex, UK.

Yohannes, M., Degefu, H., Tolosa, T., Belihu, K., Cutler, R and Cutler, S., 2013. Distribution of brucellosis in different regions in Ethiopia. Afr. J. Microbiol. Res., 7,11501157

Zinsstag, J., Taleb, M.O., Craig, P.S. 2006. Editorial: health of nomadic pastoralists: new approaches towards equity effectiveness. Trop. Med. Int. Hlth., 11(5), 565-568. 